\title{
Hexacyanoferrate-Decorated Titania Nanotube: CoHCF@TNT Modified GCE as an Electron Transfer Mediator for the Determination of Hydrazine in Water Samples
}

\author{
S. Jancy Sophia, S. Devi, and K. Pandian \\ Department of Inorganic Chemistry, University of Madras, Guindy Campus, Chennai 600 025, India \\ Correspondence should be addressed to K. Pandian, jeevapandian@yahoo.co.uk \\ Received 6 January 2012; Accepted 8 February 2012 \\ Academic Editors: S. Girousi and A. Taga
}

Copyright (C) 2012 S. Jancy Sophia et al. This is an open access article distributed under the Creative Commons Attribution License, which permits unrestricted use, distribution, and reproduction in any medium, provided the original work is properly cited.

\begin{abstract}
The cobalt hexacyanoferrate-decorated titania nanotube (CoHCF@TNT) was prepared by dispersing 100 mg of titania nanotube (TNT) to a solution of an equimolar concentration of $\mathrm{CoCl}_{2} \cdot 6 \mathrm{H}_{2} \mathrm{O}$ and $\mathrm{K}_{3}\left[\mathrm{Fe}(\mathrm{CN})_{6}\right]$ containing $0.05 \mathrm{M} \mathrm{KCl}$ solution $(35 \mathrm{~mL})$. The TNT was synthesized by hydrothermal method using Degussa P-25 $\mathrm{TiO}_{2}$ in $2 \mathrm{M} \mathrm{NaOH}$ as reported in the literature. The CoHCF@TNT was isolated and characterized by DRS-UV, FE-SEM, FT-IR, and XRD analysis. The electrochemical behavior of the CoHCF@TNT was carried out in 0.1 M phosphate buffer. The CoHCF@TNT modified system showed an excellent electron transfer mediator for the oxidation of hydrazine at $+0.5 \mathrm{~V}$ versus Ag wire. The proposed method can be utilized for the amperometry detection of hydrazine from environmental samples. A calibration plot was constructed by plotting the concentration of hydrazine against the peak current. The current response was linear in the ranges of the hydrazine concentration from $5 \times 10^{-4} \mathrm{M}$ to 2.5 $\times 10^{-3} \mathrm{M}$ with a slope of $72.8 \mu \mathrm{AmM}^{-1}$ and the linear correlation coefficient of 0.9972 . The detection limit was found to be $1 \times$ $10^{-3} \mathrm{M}$.
\end{abstract}

\section{Introduction}

There is an increasing demand for the development of a novel electrocatalytic mediator which has been used for various kinds of sensors for the detection of environmentally important pollutant in recent days. Though metal hexacyanoferrates are most studied as an important class of electron transfer mediator for the electrocatalytic oxidation and reduction, still there are numerous developments have been made to study their unique inherent physicochemical properties and electron transfer characteristics. The metal hexacyanoferrate-modified electrode shows excellent electrocatalytic behavior and selectivity. They can be widely used in various fields of research including photomagnetic [1], solid batteries [2], electrocatalysis [3], and biosensors [4]. Itaya et al., [5] and others have extensively studied the electrochemical behavior and stability of the Prussian blue and its analogues due to their similar electrochemical behavior, stability, and wider electrochemical window. These metal hexacyanoferrate-modified electrodes have mostly been utilized for the electrocatalytic detection of biological important thiols [6], selective detection of neurotransmitters [7], and environmental important pollutants like hydrazine [8], peroxide [9], and thiosulfate [10]. Because of its zeolite-like characteristics, $\mathrm{PB}$ and its analogues have been utilized for selective removal of radioactive Cs and toxic metals like $\mathrm{Tl}[11$, $12]$.

To improve the electrochemical stability of the modified electrode and avoid fouling of the electrode, various strategies have been demonstrated. For instant, sol-gel method, by using perm selective coating using nafion and other polymers and direct coating in presence of conducting polymer are some of the few examples [13, 14]. Recently mesoporous carbons [15], carbon nanotube [16], and graphene [17] have been utilized to stabilize PB and analogues. In the present work, we have taken an initiative to use titania nanotube as template to immobilize metal hexacyanoferrates. It is well known that titania and its nanotube can be used as electrode substrate for the electrocatalytic reaction and solar cell applications $[18,19]$. We have made an attempt to use titania 
nanotube as template to immobilize cobalt hexacyanoferrate by sequential deposition method [20]. The film thickness and electron transfer reaction can be controlled by the help of the sequential deposition method. The aim of the present investigation is to utilize CoHCF@TNT, for the electrocatalytic detection of hydrazine in water samples. Hydrazine is widely used in industry and agriculture as fuel cells, insecticides, explosives, rocket propellants, metal film manufactures, and pharmaceuticals [21]. Hydrazine is found to be a neurotoxin and produces carcinogenic and mutagenic effects [22]. Its poisoning induces vomiting, severe irritation of the respiratory track, and long-term exposure affects the central nervous system. Hydrazine can be determined by several instrumental methods including chromatography [23], spectrophotometry [24], capillary electrophoresis [25] and fluorimetry [26]. Among these techniques, the electrochemical method is found to be a simple and an easy way to estimate hydrazine.

Electroanalytical techniques seem to provide direct and efficient methods for the detection of hydrazine at trace level. This technique offers the opportunity for portable, cheap, and rapid methodologies. However, electrochemical oxidations of hydrazine are sluggish, and a relatively high overpotential is required at conventional electrodes. Several approaches have been investigated to minimize this problem. Therefore, chemically modified electrodes have been developed for the determination of hydrazine. Several types of modified electrode have been used for the electrocatalytic oxidation of hydrazine such as metal phthalocyanine [27, 28], metal porphyrin [29], metal hexacyanoferrate [30, 31], metal complexes [32], metal nanoparticles [33], and metal nanoparticles-modified MWCNT-[34] modified electrodes. Among these electron transfer mediators, metal hexacyanoferrates [35], metal hexacyanoferrate-modified metal oxide [36], and metal hexacyanoferrate-modified carbon nanotube [37] have been widely used for the electrocatalytic detection of hydrazine in various sources. Here, we are aiming to use CoHCF@TNT for the quantitative detection of hydrazine in water sources by amperometry method for the first time.

\section{Experimental Section}

2.1. Chemicals. All chemicals were purchased from commercial sources. $\mathrm{TiO}_{2}$ was purchased from Aldrich chemical, USA. Cobalt(II) chloride, and potassium ferricyanide, potassium chloride were used as received from SD fine chemicals Pvt, Ltd, India. All solutions were prepared using high-purity Milli-Q water (resistivity of 18.1 M $\Omega$ ).

2.2. Instrumental Method. The FT-IR spectra were recorded using Perkin-Elmer 360 model FT-IR double beam spectrophotometer. Diffusive reflectance spectrum was recorded in DRS UV-visible spectrophotometer lambda 35. XRD patterns of the samples were recorded with a JSO DEBYE FLEX 2002 Seifert diffractometer. SEM images were obtained with a field emission JEOL-JSM-6360 instrument, USA. The CV experiment was carried out using CHI 660A electrochemical instrument, USA. A three-electrode system with a single compartment cell system was used for the electrochemical studies. A GCE and platinum were used as working and counter electrode, respectively. Ag wire was used as reference electrode. All potentials were measured against the Ag wire as reference electrode.

2.3. Preparation of CoHCF@TNT-Modified GCE. The glassy carbon (GC) surface was polished to a mirror-like smoothness with emery paper and then sonicated in ethanol and distilled water for 5 minutes. Following drying with a stream of high purity of nitrogen gas, the GC substrate was modified with drops of CoHCF@TNT suspension and then dried. A CoHCF@TNT-coated GC electrode was thus prepared for measurements, after the GC was removed from the deposited solution throughly rinsed with water, and dried with nitrogen gas.

2.4. Synthesis of TNT. We have synthesized TNT based on previous literature report [38]. In brief, $2 \mathrm{~g}$ of the $\mathrm{TiO}_{2}(\mathrm{P}-$ 25 Degussa) was mixed with $70 \mathrm{~mL}$ of $10 \mathrm{~N} \mathrm{NaOH}$ solution, and the resulting homogeneous mixture was allowed to heat treatment at $110-150^{\circ} \mathrm{C}$ in a Teflon-lined autoclave for $24 \mathrm{~h}$. After the treatment, the filtered sample was then neutralized by mixing with $1 \mathrm{~L}$ of $0.1 \mathrm{~N} \mathrm{HCl}$ solutions for several times, until the $\mathrm{pH}$ value of the rinsing solution was less than 7 . The powder was dried at $100^{\circ} \mathrm{C}$ for $3 \mathrm{~h}$ to give the as-synthesized nanotube product. To improve the thermal stability, the as-synthesized nanotubes were calcined at different temperatures for $1 \mathrm{~h}$. The appearance of white color powder indicates the formation of TNT. The CoHCF@TNT was prepared by using an equimolar concentration of $\mathrm{CoCl}_{2} \cdot 6 \mathrm{H}_{2} \mathrm{O}$ and $\mathrm{K}_{3}\left[\mathrm{Fe}(\mathrm{CN})_{6}\right]$ containing $0.05 \mathrm{M}$ $\mathrm{KCl}$ solution in presence of $100 \mathrm{mg}$ of TNT [39]. Finally, the CoHCF@TNT was thoroughly washed with ultrapure water to remove the physisorbed ions. The CoHCF@TNT is dried under nitrogen atmosphere for overnight and stored in a dark.

\section{Results and Discussion}

3.1. SEM Images of CoHCF@TNT. Figure 1(a) depicted the typical SEM images of products prepared by hydrothermal treatments of P-25 Degussa type $\mathrm{TiO}_{2}$ at $383 \mathrm{~K}$ for $24 \mathrm{~h}$. Furthermore, the effect of the sodium content on the microstructure of nanotubes is important. Therefore, energy-dispersive X-ray (EDX) (Figure 2(a)) evaluation was carried out for products prepared by hydrothermal treatment for $24 \mathrm{~h}$. The $\mathrm{Na} / \mathrm{Ti}$ atomic ratio for products prepared by hydrothermal treatment for $24 \mathrm{~h}$ was approximately 0.2 without acid treatment. On the contrary, after acid treatment with a $0.1 \mathrm{M} \mathrm{HCl}$ aqueous solution, only a trace amount of sodium could be detected in this sample by EDX analysis (Figure 2(b)). This has been ascribed to the decrease of $\mathrm{Na} / \mathrm{Ti}$ ratio of $\mathrm{TiO}_{2}$-derived TNT caused by the replacement of $\mathrm{Na}^{+}$ with $\mathrm{H}^{+}$during the acid treatment with dil. $\mathrm{HCl}$ [40].

SEM image of CoHCF@TNT is shown in Figure 1(b). From SEM analysis, the size and shape of the nanotube were calculated. After exposure of the CoHCF solution, the nanotubes are aggregated and form a big-size composite 


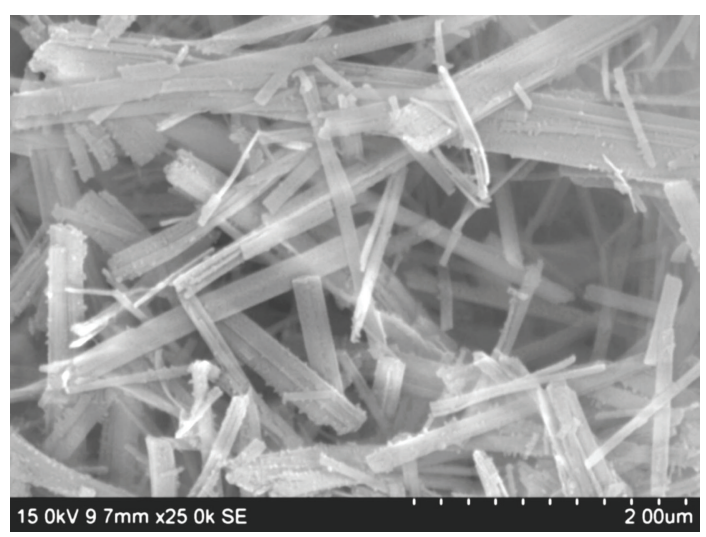

(a)

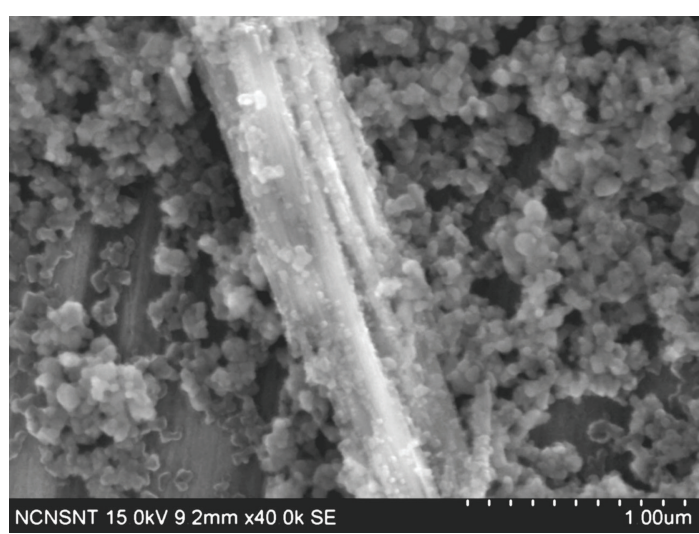

(b)

Figure 1: SEM images of TNT (a) and after modifying with CoHCF (b).

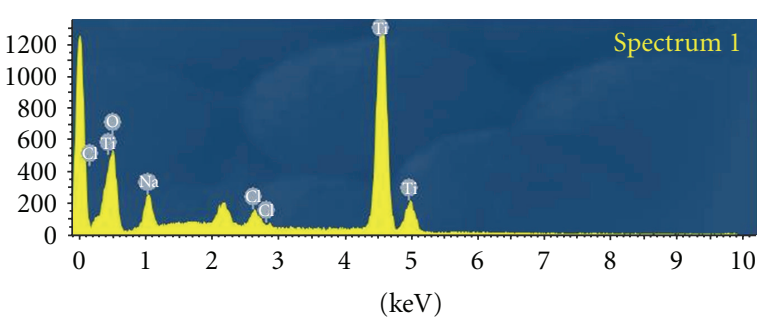

(a)

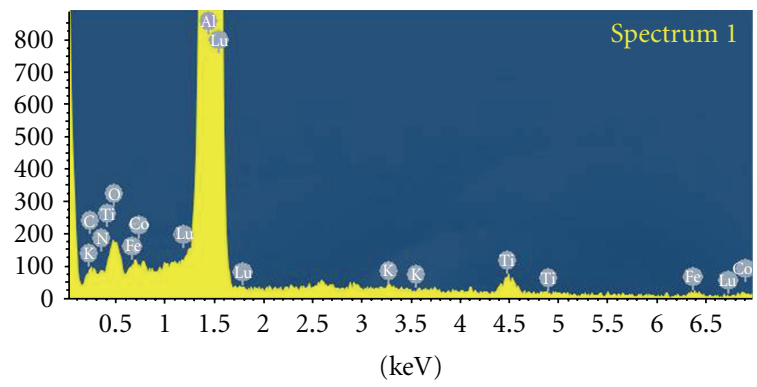

(b)

Figure 2: EDAX images of TNT (a) and after modifying with CoHCF (b).

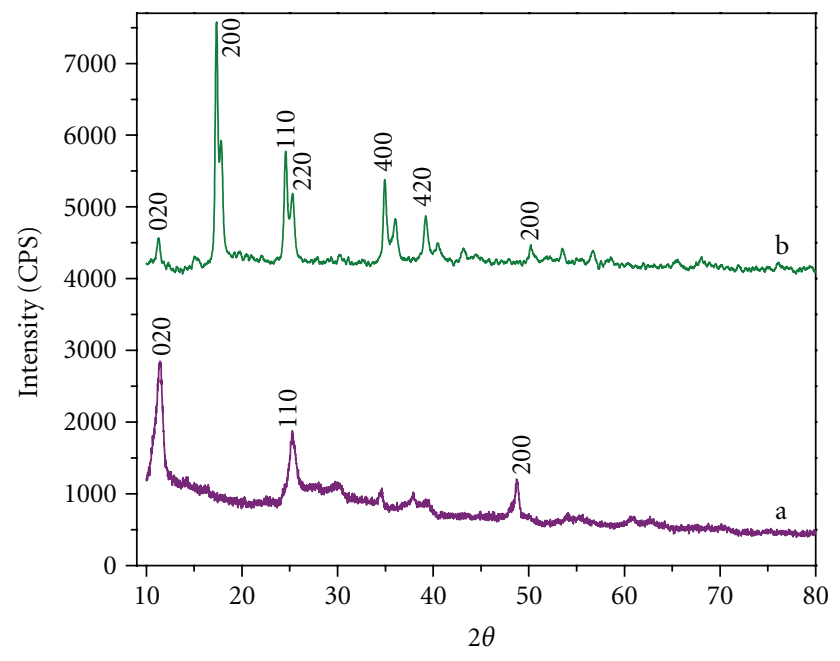

FIGURE 3: XRD pattern of (a) TNT (b) CoHCF@TNT.

fiber-like structure. The approximate composition of CoHCF treated TNT was calculated from EDX analysis.

3.2. XRD Pattern of CoHCF@TNT. The XRD pattern of pure TNTs and CoHCF@TNT is shown in Figure 3. The XRD pattern profile of the TNTs is exactly similar to those observed in the literature [41], which suggests a crystalline structure of lepidocrocite-type TNTs with a general formula $\mathrm{H}_{x} \mathrm{Ti}_{2-x / 4} \square_{x / 4} \mathrm{O}_{4}$ ( $\square$ : vacancy). The X-ray diffractograms are typical of layered materials, which suggest that the nanotubes are multiwalled in nature. The layered structures give rise to a characteristic (200) reflection with a lower $2 \theta$ values of $11.3^{\circ}$ which corresponds to interlayer distance of TNT. The peak position shows red shift when compared with the literature reports, and it is due to the sodium ions present in the TNT interlayers. A high-intense peak at $2 \theta=48.6^{\circ}$ was found, and it is due to the edge sharing $\mathrm{TiO}_{6}$ octahedral. The other peaks at $2 \theta \sim 25.1$ correspond to the titanate phase. All other peaks are in close agreement with reported values. The (200) peak at $11.3^{\circ}$ was not altered even after intercalation of CoHCF into TNT lattices, indicating that the interlayer spacing was not expanded with intercalation of $\mathrm{CoHCF}$ into the interlayer of TNT. The X-ray powder diffraction (XRD) pattern of the composite material showed peaks at $17.32^{\circ}(200), 25.48^{\circ}(220), 34.86^{\circ}(400)$, and $39.05^{\circ}(420)$, which can be indexed as the face-centred cubic (fcc) crystal structure [42].

3.3. UV-Vis Diffuse Reflectance Spectra. UV-Vis diffuse reflectance spectroscopy is used to measure the change in the electronic absorption spectrum of the materials. Figure 4 shows the UV-Vis absorption spectra of TNT, (b) CoHCF, 


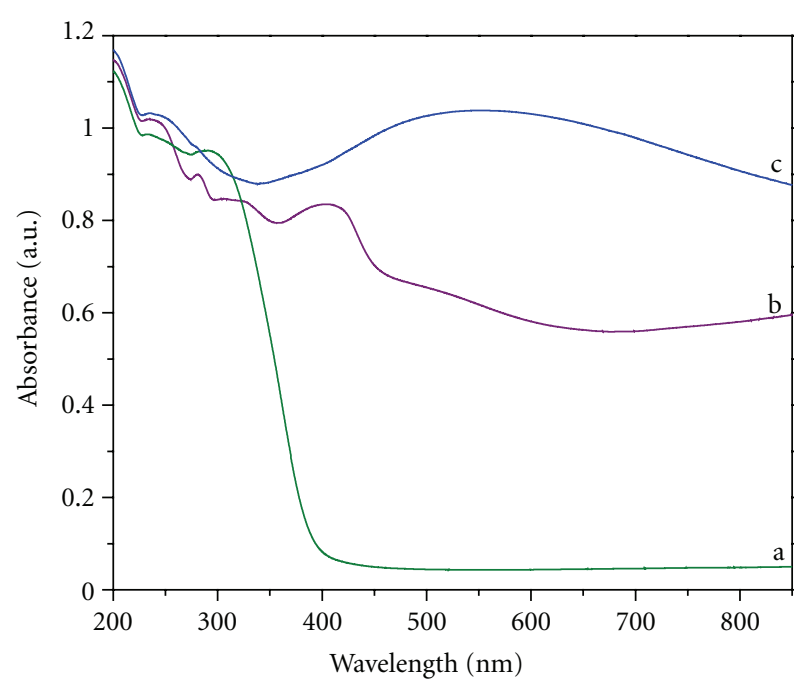

FIgure 4: UV-Vis diffuse reflectance spectrum of TNT (a), CoHCF (b), and CoHCF@TNT (c).

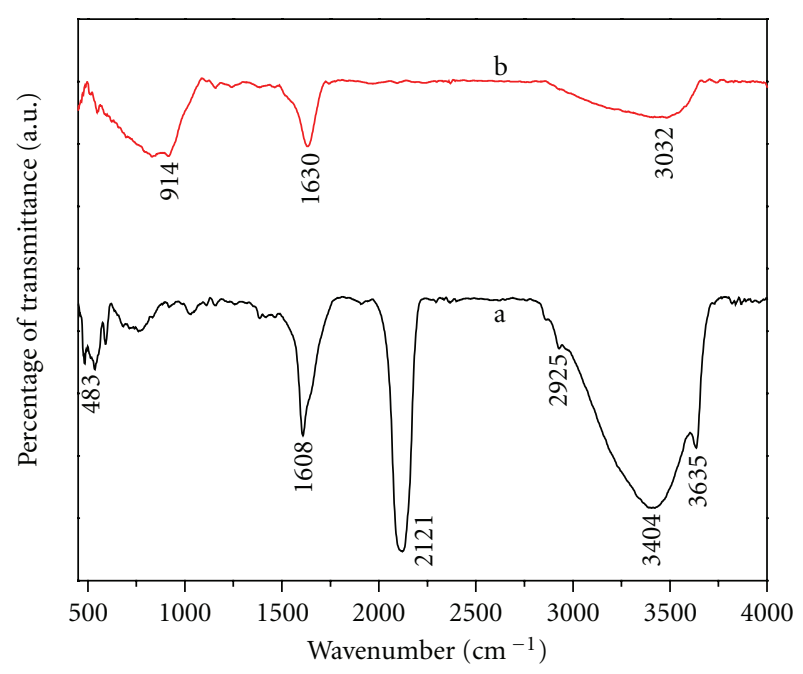

FIgure 5: FT-IR spectra of (a) CoHCF@TNT (b) TNT.

and (c) CoHCF@TNT. It is evident that for the protonic lepidocrocite TNT, there is broadband absorption from 268 to $314 \mathrm{~nm}$, due to the transition from the $\mathrm{O}^{2-}$ antibonding orbital to the lowest empty orbital of $\mathrm{Ti}^{4+}$. The addition of CoHCF to the TNT structure shifts the band edge absorption to about $410 \mathrm{~nm}$, thus making it possible to use these CoHCF@TNTs as photocatalysts operating with excitation in the violet-blue region of the electromagnetic spectrum. This red shift in the band edge absorption can be understood as being due to the effects of CoHCF addition (intercalation), which change the band gap energy of the system. A similar band gap shift toward the visible range was also observed for TNTs intercalated with other metals, such as $\mathrm{Fe}, \mathrm{Bi}, \mathrm{Cd}$, Ni, and Co [43]. By using standard Kubelka-Munk methodology, we can estimate the band gap for TNT and CoHCF as being 3.06 and $2.94 \mathrm{eV}$, respectively. The photoabsorption of CoHCF@TNT in the range 410-760 nm is attributed due

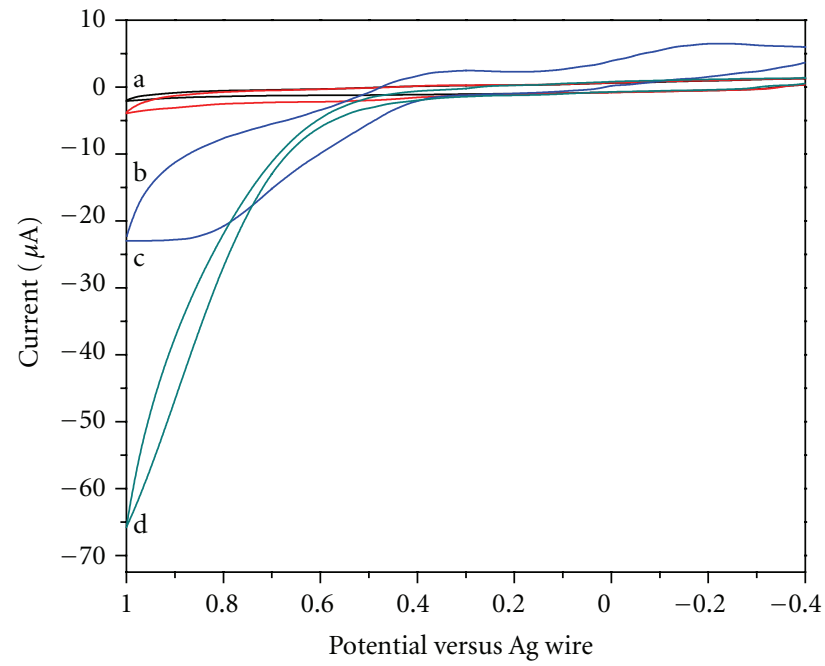

Figure 6: Cyclic voltammograms of (a) bare, (b) bare with $0.1 \mathrm{mM}$ hydrazine, (c) CoHCF@TNT-modified GC electrode and (d) same as (c) in $0.1 \mathrm{mM}$ hydrazine at $\mathrm{pH} 7$ (0.1 M phosphate buffer): scan rate: $50 \mathrm{mV} / \mathrm{sec}$.

to the existence of the Co $3 \mathrm{~d}$ bands above the O $2 \mathrm{p}$ bands $[43,44]$.

3.4. FT-IR Spectral Studies for TNT and CoHCF@TNT. The formation of CoHCF@TNT was further confirmed by the FTIR spectrum. Figure 5 shows the FTIR spectrum of (a) CoHCF@TNT; (b) TNT. In the FT-IR spectrum of TNT (Figure 5(b)), three absorption bands centered at 1630, 3482, and $914 \mathrm{~cm}^{-1}$ are assigned for bending vibration of $\mathrm{H}-\mathrm{O}-$ $\mathrm{H}$, stretching vibrations of $\mathrm{OH}$ group of physisorbed water and Ti-O bonds, respectively. These results indicate the most replacement of $\mathrm{Na}^{+}$in the nanotubular product by $\mathrm{H}^{+}$and also the presence of large amount of water molecules and hydroxyl groups present in TNT. A band at $914 \mathrm{~cm}^{-1}$ was affected by the intercalation of CoHCF, which leads to a decrease in vibrational energy of the $\mathrm{Ti}-\mathrm{O}$ octahedrons. The changes in the stretching modes for terminal Ti-O bonds $\left(914 \mathrm{~cm}^{-1}\right)$ was understood in terms of the interaction of the CoHCF with the terminal Ti-O bonds. In the FT-IR spectra of CoHCF@TNT, the intense and a strong absorption band at $2121 \mathrm{~cm}^{-1}$ is due to the common characteristics of CoHCF and its analogues, corresponding to the stretching vibration of the $-\mathrm{C} \equiv \mathrm{N}$-group, and the absorption band at $483 \mathrm{~cm}^{-1}$ is due to the formation of $\mathrm{M}-\mathrm{CN}-\mathrm{M}$, which indicate the presence of CoHCF. In addition, the absorption bands at 3404 and $1608 \mathrm{~cm}^{-1}$ indicates the $\mathrm{O}-\mathrm{H}$ stretching mode and $\mathrm{H}-$ $\mathrm{O}-\mathrm{H}$ bending mode, respectively. These results highlight the presence of water molecules in a interstitial position, and also the stretching vibration of water molecules produces another broad peak at $3635 \mathrm{~cm}^{-1}$ which further confirm that the samples are hydrated $[40,43,45]$.

3.5. Electrochemical Behavior of CoHCF@TNT. The electrochemical behavior of the CoHCF@TNT was investigated using cyclic voltammetric technique (Figure 6). A reversible cyclic voltammogram is obtained for the CoHCF@TNT 
TABLE 1: A comparison of electrocatalytic detection of hydrazine using various types of modified electrode systems.

\begin{tabular}{|c|c|c|c|c|c|}
\hline S. numbers & Electrode system & $\mathrm{pH}$ & Potential & $\begin{array}{c}\text { Concentration } \\
\text { ranges }\end{array}$ & Reference \\
\hline (1) & $\mathrm{CeHCF} /$ mesoporous carbon & 1.5 & $+0.34 \mathrm{~V}$ versus $\mathrm{Ag} / \mathrm{AgCl}($ satd $\mathrm{KCl})$ & $1-163 \mu \mathrm{M}$ & {$[14]$} \\
\hline$(2)$ & $\begin{array}{l}\text { Ni(II)-bicalein } \\
\text { complex/MWCNT }\end{array}$ & 13 & $+0.65 \mathrm{~V}$ versus $\mathrm{Ag} / \mathrm{AgCl}($ satd $\mathrm{KCl})$ & $2.5 \mu \mathrm{M}$ to $0.2 \mathrm{mM}$ & {$[21]$} \\
\hline (3) & $\mathrm{Pd} /$ boron-doped diamond & 7 & $+0.11 \mathrm{~V}$ versus $\mathrm{Ag} / \mathrm{AgCl}($ satd $\mathrm{KCl})$ & $10 \mathrm{mM}$ to $102 \mathrm{mM}$. & {$[20]$} \\
\hline (4) & $\mathrm{Pd} / \mathrm{CNT}$ & 1 & 0.27 versus $\mathrm{Ag} / \mathrm{AgCl}$ (satd $\mathrm{KCl})$ & $2.5-700 \mu \mathrm{M}$ & {$[33]$} \\
\hline$(5)$ & CoHCF@TNT & 6.9 & $+0.50 \mathrm{~V}$ versus $\mathrm{Ag}$ wire & $0.5-2.5 \mathrm{mM}$ & Present work \\
\hline
\end{tabular}

TABLE 2: Determination of hydrazine in real samples.

\begin{tabular}{|c|c|c|c|c|}
\hline Samples & Added $/ 10^{-4} \mathrm{M}$ & Found $/ 10^{-4} \mathrm{M}$ & Recovery (\%) & Average recovery (\%) \\
\hline \multirow{4}{*}{ River water } & 10 & 10.1 & 101 & \multirow{4}{*}{102.5} \\
\hline & 15 & 15.3 & 102 & \\
\hline & 20 & 21.2 & 106 & \\
\hline & 25 & 25.2 & 100.8 & \\
\hline \multirow{4}{*}{ Drinking water } & 10 & 9.9 & 99 & \multirow{4}{*}{103.2} \\
\hline & 15 & 16.2 & 108 & \\
\hline & 20 & 21.1 & 106 & \\
\hline & 25 & 24.9 & 99.6 & \\
\hline
\end{tabular}

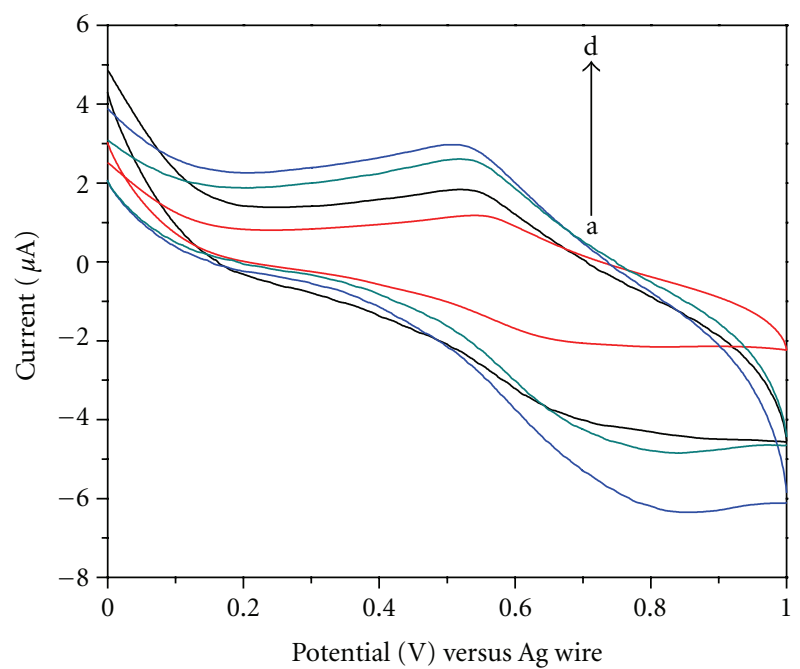

Figure 7: Cyclic voltammograms of CoHCF@TNT-modified electrode in $0.1 \mathrm{M}$ phosphate buffer $(\mathrm{pH} 7)$ at scan rates of 20, 50, 75, and $100 \mathrm{mV} \mathrm{s}^{-1}$ (bottom to top).

in $0.1 \mathrm{M}$ PBS medium. The cyclic voltammogram of CoHCF@TNT-modified electrodes exhibits an enhancement in redox signals, which confirms the high sensitivity of the electrode and also confirms the modification of TNT by CoHCF.

We have compared the current density and the peak potential changes of bare and CoHCF@TNT-modified electrodes on electrocatalytic oxidation of hydrazine, and the resulting cyclic voltammograms are shown in Figure 6. It was observed that there is a decrease in over potential for CoHCF@TNT modified electrode than the bare GCE. Also there is a remarkable increase in the anodic peak current were noted in the case of CoHCF@TNT modified electrode. This result confirms that the CoHCF@TNT acts as a better electrocatalyst on electrochemical oxidation of hydrazine at neutral $\mathrm{pH}$ ranges.

The electrochemical behavior of CoHCF@TNT was tested in $0.1 \mathrm{M}$ PBS, and the resulting voltammogram is shown in Figure 7. From the cyclic voltammogram, it can be seen that the redox peak current for both $\mathrm{Co}^{2+} / \mathrm{Co}^{3+}$ and $\mathrm{Fe}(\mathrm{CN})_{6}{ }^{4-} / \mathrm{Fe}(\mathrm{CN})_{6}{ }^{3-}$ systems, and the separate redox peaks were merged together and showing a single redox peak. The increase in peak currents when increasing potential scan rates, confirming the redox behavior is due to the surface confinement of the redox species and also suggests that the redox reaction is purely diffusion-controlled one [30].

\section{Amperometric Response of CoHCF@TNT}

Because of the increase in peak at $0.5 \mathrm{~V}$ in Figure 8 for the electrochemical oxidation of hydrazine using CoHCF@TNT many fold when compared with bare GCE, we have developed amperometry method for the quantitative detection of hydrazine in water samples. The typical hydrazine current response at $0.5 \mathrm{~V}$ versus $\mathrm{Ag}$ wire during the successive addition of $50 \mu \mathrm{L}$ of $0.1 \mathrm{M}$ hydrazine in $8 \mathrm{~mL} 0.1 \mathrm{M}$ PBS under constant stirring condition and the resulting current response at regular time intervals are shown in Figure 8. A well-defined amperometric response with a response time of less than $5 \mathrm{~s}$ was observed, which demonstrates the stable and efficient catalytic ability of CoHCF@TNT. The response current was linear with the hydrazine concentration from $5 \times$ $10^{-4} \mathrm{M}$ to $2.5 \times 10^{-3} \mathrm{M}$ with a slope of $72.8 \mu \mathrm{AmM}^{-1}$ and linear correlation coefficient of 0.9972 . The detection limit was found to be $1 \times 10^{-3} \mathrm{M}$. The detection limit value is 


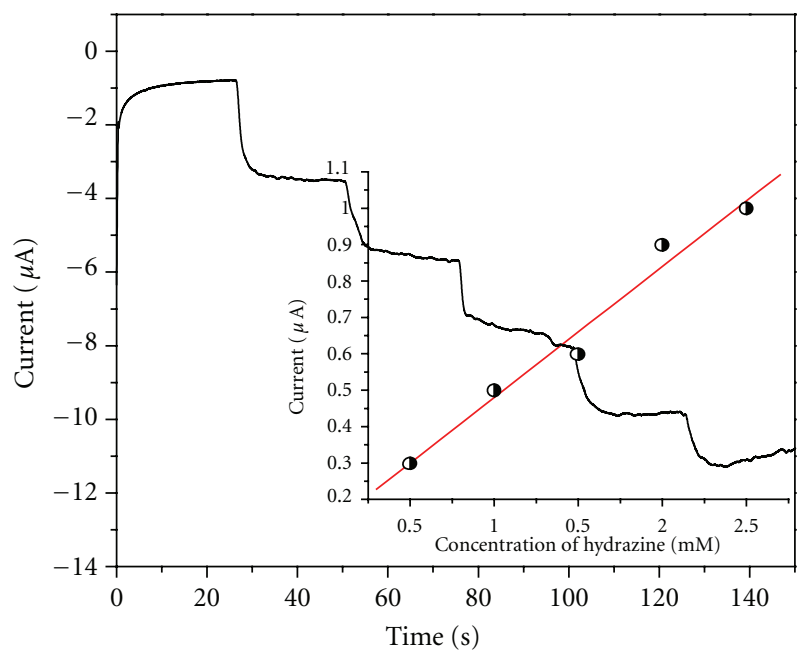

Figure 8: Amperometric response of CoHCF@TNT in 0.1 M phosphate buffer medium by successive addition of $50 \mu \mathrm{L}$ hydrazine. Applied potential: $+0.5 \mathrm{~V}$. (Inset figure plot of ip versus $\mathrm{c}$ hydrazine).

comparable with the reported in the literature which was shown in Table 1.

For the detection of hydrazine in real water samples, standard addition method was carried out. The results are given in Table 2 for triplicate, and the results were consistent. The recovery was found to close to $100 \%$ in most cases.

\section{Conclusion}

In conclusion, we have successfully developed a methodology for synthesis of CoHCF@TNT. The surface morphology and structural features of the system were investigated by using various instrumental methods such as scanning electron microscopy (SEM), X-ray powder diffraction method (XRD), and FT-IR spectrophotometer. The electrochemical behavior of the CoHCF@TNT was investigated using cyclic voltammetry technique, and the cyclic voltammogram of CoHCF@TNT showed reversible electron transfer behavior of CoHCF. The CoHCF@TNT-modified GC electrode showed an excellent electrocatalytic oxidation of hydrazine in $0.1 \mathrm{M}$ PBS medium. An enhanced electrochemical response was noted when compared with bare GCE with lower over potential ranges. For the quantitative detection of hydrazine, the amperometry method was adopted under optimum experimental conditions with an operating potential of $0.5 \mathrm{~V}$ versus Ag wire. This proposed method can be applied for quantitative detection of hydrazine in water samples. The results were given in a tabular form, and it was found that the electrochemical response stable for repeated usage of the electrode without loss of its activity.

\section{Acknowledgments}

The authors are expressing grateful thanks to National Center for Nanoscience and Nanotechnology, University of Madras for providing SEM facility, CIF, Pondicherry University, India, for providing FT-IR facility, Dr. K. Sivakumar
A.C.Tech, Anna University for providing DRS UV, and Dr. K. Sivakumar, Department of Physics, Anna university for providing XRD facility. K. Pandian is grateful to CSIR, New Delhi, India, for providing financial assistant to carry out a part of the investigation.

\section{References}

[1] S. I. Ohkoshi, S. Yorozu, O. Sato, T. Iyoda, A. Fujishima, and K. Hashimoto, "Photoinduced magnetic pole inversion in a ferro-ferrimagnet: $\left(\mathrm{Fe}_{0.40}^{I I} \mathrm{Mn}_{0.60}^{I I}\right)_{1.5} \mathrm{Cr}^{I I I}(\mathrm{CN})_{6}$," Applied Physics Letters, vol. 70, no. 8, pp. 1040-1042, 1997.

[2] M. Jayalakshmi and F. Scholz, "Performance characteristics of zinc hexacyanoferrate/prussian blue and copper hexacyanocferrate/Prussian blue solid state secondary cells," Journal of Power Sources, vol. 91, no. 2, pp. 217-223, 2000.

[3] A. A. Karyakin, "Prussian blue and its analogues: electrochemistry and analytical applications," Electroanalysis, vol. 13, no. 10, pp. 813-819, 2001.

[4] A. A. Karyakin, E. E. Karyakina, and L. Gorton, "Amperometric biosensor for glutamate using Prussian Blue-based 'artificial peroxidase' as a transducer for hydrogen peroxide," Analytical Chemistry, vol. 72, no. 7, pp. 1720-1723, 2000.

[5] K. Itaya, N. Shoji, and I. Uchida, "Catalysis of the reduction of molecular oxygen to water at Prussian blue modified electrodes," Journal of the American Chemical Society, vol. 106, no. 12, pp. 3423-3429, 1984.

[6] M. Liu, P. Li, Y. Cheng, Y. Xian, C. Zhang, and L. Jin, "Determination of thiol compounds in rat striatum microdialysate by HPLC with a nanosized CoHCF-modified electrode," Analytical and Bioanalytical Chemistry, vol. 380, no. 5-6, pp. 742750, 2004.

[7] Z. Xun, C. Cai, W. Xing, and T. Lu, "Electrocatalytic oxidation of dopamine at a cobalt hexacyanoferrate modified glassy carbon electrode prepared by a new method," Journal of Electroanalytical Chemistry, vol. 545, pp. 19-27, 2003.

[8] A. De Morais, F. L. Pissetti, A. M. S. Lucho, and Y. Gushikem, "Influence of copper hexacyanoferrate film thickness on the electrochemical properties of self-assembled 3-mercaptopropyl gold electrode and application as a hydrazine sensor," Journal of Solid State Electrochemistry, vol. 14, no. 8, pp. 13831390, 2010.

[9] H. Razmi and A. Taghvimi, "Tin hexacyanoferrate nanoparticles based electrochemical sensor for selective and high sensitive determination of $\mathrm{H}_{2} \mathrm{O}_{2}$ in acidic media," International Journal of Electrochemical Science, vol. 5, no. 6, pp. 751-762, 2010.

[10] H. Green-Pedersen and G. V. Korshin, "Separation of cesium from high ionic strength solutions using a cobalt hexacyanoferrate-modified graphite electrode," Environmental Science and Technology, vol. 33, no. 15, pp. 2633-2637, 1999.

[11] F. A. Adekola, N. G. Nwaogu, and N. A. Salam, "Removal of cadmium from aqueous solution using manganese hexacyanoferrates(II)/(III)," Bulletin of the Chemical Society of Ethiopia, vol. 21, no. 2, pp. 221-228, 2007.

[12] M. Zhang, Z. Jin, J. Zhang et al., "Effect of annealing temperature on morphology, structure and photocatalytic behavior of nanotubed $\mathrm{H}_{2} \mathrm{Ti}_{2} \mathrm{O}_{4}(\mathrm{OH})_{2}$," Journal of Molecular Catalysis A, vol. 217, no. 1-2, pp. 203-210, 2004.

[13] M. Deepa, A. Awadhia, and S. Bhandari, "Electrochemistry of poly(3,4-ethylenedioxythiophene)-polyaniline/Prussian blue electrochromic devices containing an ionic liquid based gel electrolyte film," Physical Chemistry Chemical Physics, vol. 11, no. 27 , pp. 5674-5685, 2009. 
[14] N. R. Stradiotto, S. S. L. Castro, R. J. Mortimer, and M. F. De Oliveira, "Electrooxidation and determination of dopamine

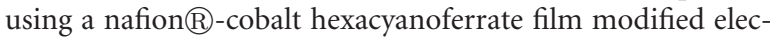
trode," Sensors, vol. 8, no. 3, pp. 1950-1959, 2008.

[15] H. Yang, B. Lu, L. Guo, and B. Qi, "Cerium hexacyanoferrate/ordered mesoporous carbon electrode and its application in electrochemical determination of hydrous hydrazine," Journal of Electroanalytical Chemistry, vol. 650, no. 2, pp. 171-175, 2011.

[16] A. S. Adekunle and K. I. Ozoemena, "Electrocatalytic oxidation of diethylaminoethanethiol and hydrazine at singlewalled carbon nanotubes modified with Prussian blue nanoparticles," Electroanalysis, vol. 22, no. 21, pp. 2519-2528, 2010.

[17] Y. Bo, W. Wang, J. Qi, and S. Huang, "A DNA biosensor based on graphene paste electrode modified with Prussian blue and chitosan ," Analyst, vol. 136, no. 9, pp. 1946-1951, 2011.

[18] S. Liu and A. Chen, "Coadsorption of horseradish peroxidase with thionine on $\mathrm{TiO}_{2}$ nanotubes for biosensing," Langmuir, vol. 21, no. 18, pp. 8409-8413, 2005.

[19] Y. Ohsaki, N. Masaki, T. Kitamura et al., "Dye-sensitized $\mathrm{TiO}_{2}$ nanotube solar cells: fabrication and electronic characterization," Physical Chemistry Chemical Physics, vol. 7, no. 24, pp. 4157-4163, 2005.

[20] D. Ivekoviç, A. Gajoviç, M. Ceh, and B. Pihlar, "Prussian bluemodified titanate nanotubes: a novel nanostructured catalyst for electrochemical reduction of hydrogen peroxide," Electroanalysis, vol. 22, no. 19, pp. 2202-2210, 2010.

[21] L. Zheng and J. F. Song, "Ni(II)-baicalein complex modified multi-wall carbon nanotube paste electrode toward electrocatalytic oxidation of hydrazine," Talanta, vol. 79, no. 2, pp. 319-326, 2009.

[22] C. Batchelor-McAuley, C. E. Banks, A. O. Simm, T. G. J. Jones, and R. G. Compton, "The electroanalytical detection of hydrazine: a comparison of the use of palladium nanoparticles supported on boron-doped diamond and palladium plated BDD microdisc array," Analyst, vol. 131, no. 1, pp. 106-110, 2006.

[23] M. Mori, K. Tanaka, Q. Xu, M. Ikedo, H. Taoda, and W. $\mathrm{Hu}$, "Highly sensitive determination of hydrazine ion by ionexclusion chromatography with ion-exchange enhancement of conductivity detection," Journal of Chromatography A, vol. 1039, no. 1-2, pp. 135-139, 2004.

[24] M. George, K. S. Nagaraja, and N. Balasubramanian, "Spectrophotometric determination of hydrazine," Talanta, vol. 75, no. 1, pp. 27-31, 2008.

[25] W. C. Yang, A. M. Yu, Y. Q. Dai, and H. Y. Chen, "Determination of hydrazine compounds by capillary electrophoresis with a poly (glutamic acid) modified microdisk carbon fiber electrode," Analytical Letters, vol. 33, no. 15, pp. 3343-3353, 2000.

[26] A. Safavi and A. A. Ensafi, "Kinetic spectrophotometric determination of hydrazine," Analytica Chimica Acta, vol. 300, no. 1-3, pp. 307-311, 1995.

[27] R. Baker, D. P. Wilkinson, and J. Zhang, "Comparison of two new substituted iron phthalocyanincs as electrocatalysts for he oxygen reduction and hydrazine oxidation reaction," in Proceedings of the 214th ECS Meeting/PRiME, Physical, Analytical, and Spectro-Electrochemistry General, vol. 16 of ECS Transactions, no. 28, pp. 43-61, Honolulu, Hawaii,USA, October 2008.

[28] X. Li, S. Zhang, and C. Sun, "Fabrication of a covalently attached multilayer film electrode containing cobalt phthalocyanine and its electrocatalytic oxidation of hydrazine," Journal of Electroanalytical Chemistry, vol. 553, pp. 139-145, 2003.
[29] S. M. Chen, M. F. Lu, and K. C. Lin, "The interaction of watersoluble manganese porphyrins with DNA films and their electrocatalytic properties with hydrazine," Electroanalysis, vol. 17, no. 10, pp. 847-856, 2005.

[30] S. J. Richard Prabakar and S. Sriman Narayanan, "Amperometric determination of hydrazine using a surface modified nickel hexacyanoferrate graphite electrode fabricated following a new approach," Journal of Electroanalytical Chemistry, vol. 617, no. 2, pp. 111-120, 2008.

[31] H. Razmi, A. Azadbakht, and M. H. Sadr, "Application of a palladium hexacyanoferrate film-modified aluminum electrode to electrocatalytic oxidation of hydrazine," Analytical Sciences, vol. 21, no. 11, pp. 1317-1323, 2005.

[32] A. Benvidi, P. Kakoolaki, H. R. Zare, and R. Vafazadeh, "Electrocatalytic oxidation of hydrazine at a $\mathrm{Co}(\mathrm{II})$ complex multi-wall carbon nanotube modified carbon paste electrode," Electrochimica Acta, 2010.

[33] N. Maleki, A. Safavi, E. Farjami, and F. Tajabadi, "Palladium nanoparticle decorated carbon ionic liquid electrode for highly efficient electrocatalytic oxidation and determination of hydrazine," Analytica Chimica Acta, vol. 611, no. 2, pp. 151$155,2008$.

[34] J. Zhao, M. Zhu, M. Zheng, Y. Tang, Y. Chen, and T. $\mathrm{Lu}$, "Electrocatalytic oxidation and detection of hydrazine at carbon nanotube-supported palladium nanoparticles in strong acidic solution conditions," Electrochimica Acta, vol. 56, no. 13, pp. 4930-4936, 2011.

[35] J. Zheng, Q. Sheng, L. Li, and Y. Shen, "Bismuth hexacyanoferrate-modified carbon ceramic electrodes prepared by electrochemical deposition and its electrocatalytic activity towards oxidation of hydrazine," Journal of Electroanalytical Chemistry, vol. 611, no. 1-2, pp. 155-161, 2007.

[36] S. M. Chen, M. H. Wu, and R. Thangamuthu, "Preparation, characterization, and electrocatalytic properties of cobalt oxide and cobalt hexacyanoferrate hybrid films," Electroanalysis, vol. 20, no. 2, pp. 178-184, 2008.

[37] B. Fang, R. Shen, W. Zhang, G. Wang, and C. Zhang, "Electrocatalytic oxidation of hydrazine at a chromium hexacyanoferrate/ single-walled carbon nanotube modified glassy carbon electrode," Microchimica Acta, vol. 165, no. 1-2, pp. 231-236, 2009.

[38] T. Kasuga, M. Hiramatsu, A. Hoson, T. Sekino, and K. Niihara, "Formation of titanium oxide nanotube," Langmuir, vol. 14, no. 12, pp. 3160-3163, 1998.

[39] A. A. A. Hajjaj, B. Zamora, D. V. Bavykin, A. A. Shah, F. C. Walsh, and E. Reguera, "Sorption of hydrogen onto titanate nanotubes decorated with a nanostructured $\mathrm{Cd}_{3}\left[\mathrm{Fe}(\mathrm{CN})_{6}\right]_{2}$ Prussian Blue analogue," International Journal of Hydrogen Energy, vol. 37, pp. 318-326, 2012.

[40] A. Nakahira, T. Kubo, and C. Numako, "Formation mechanism of $\mathrm{TiO} 2$-derived titanate nanotubes prepared by the hydrothermal process," Inorganic Chemistry, vol. 49, no. 13, pp. 5845-5852, 2010.

[41] W. Alves, A. O. Ribeiro, M. V.B. Pinheiro et al., "Quenching of photoactivity in phthalocyanine copper(II) -titanate nanotube hybrid systems," Journal of Physical Chemistry C, vol. 115, no. 24, pp. 12082-12089, 2011.

[42] M. Yamada, T. Tsuji, M. Miyake, and T. Miyazawa, "Fabrication of a tubular FeCo bimetallic nanostructure using a cellulose-cobalt hexacyanoferrate composite as a precursor," Chemical Communications, no. 12, pp. 1538-1540, 2009.

[43] B. C. Viana, O. P. Ferreira, A. G. Souza Filho et al., "Decorating titanate nanotubes with $\mathrm{CeO} 2$ nanoparticles," Journal of Physical Chemistry C, vol. 113, no. 47, pp. 20234-20239, 2009. 
[44] Y. Mao and S. S. Wong, "Size- and shape-dependent transformation of nanosized titanate into analogous anatase titania nanostructures," Journal of the American Chemical Society, vol. 128, no. 25, pp. 8217-8226, 2006.

[45] C. Wang, L. Zhang, Z. Guo et al., "A new amperometric hydrazine sensor based on prussian blue/single-walled carbon nanotube nanocomposites," Electroanalysis, vol. 22, no. 16, pp. 1867-1872, 2010. 


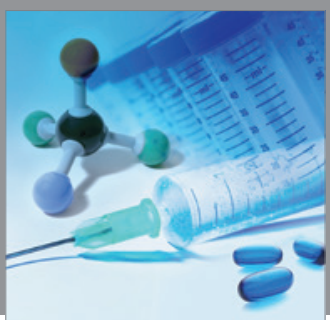

International Journal of

Medicinal Chemistry

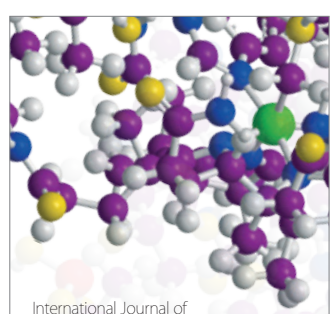

Carbohydrate Chemistry

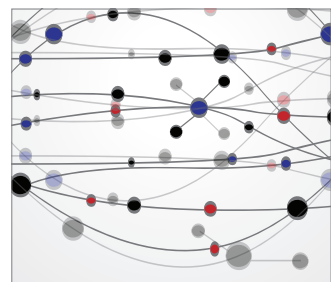

The Scientific World Journal
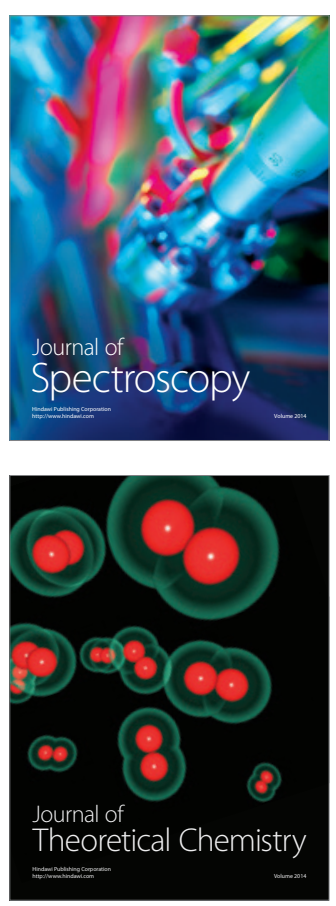
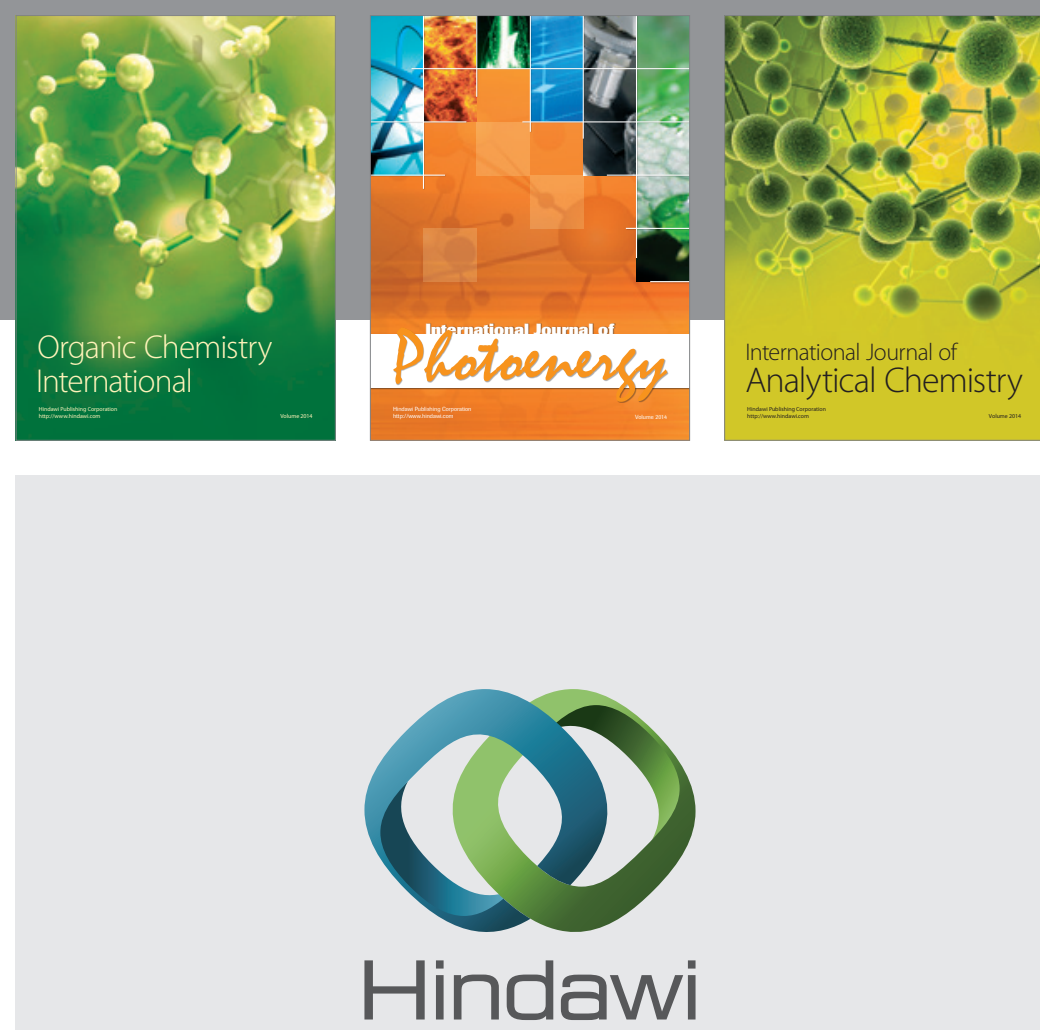

Submit your manuscripts at

http://www.hindawi.com
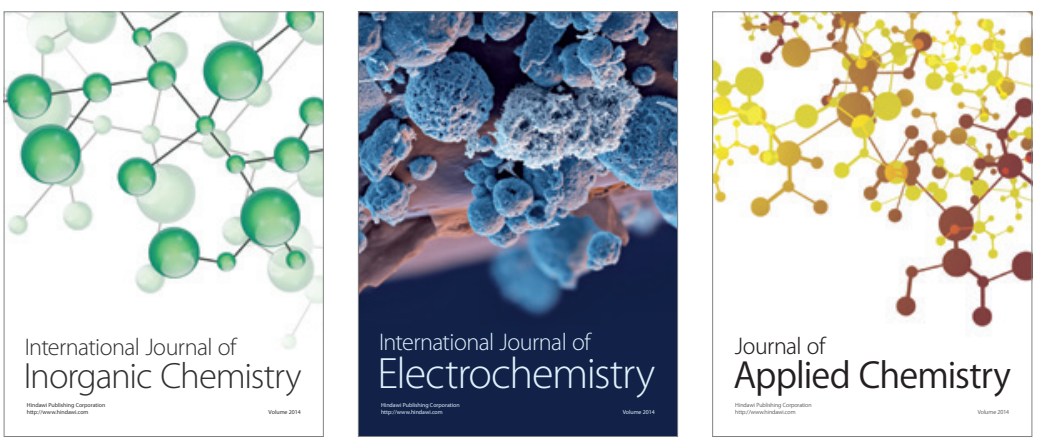

Journal of

Applied Chemistry
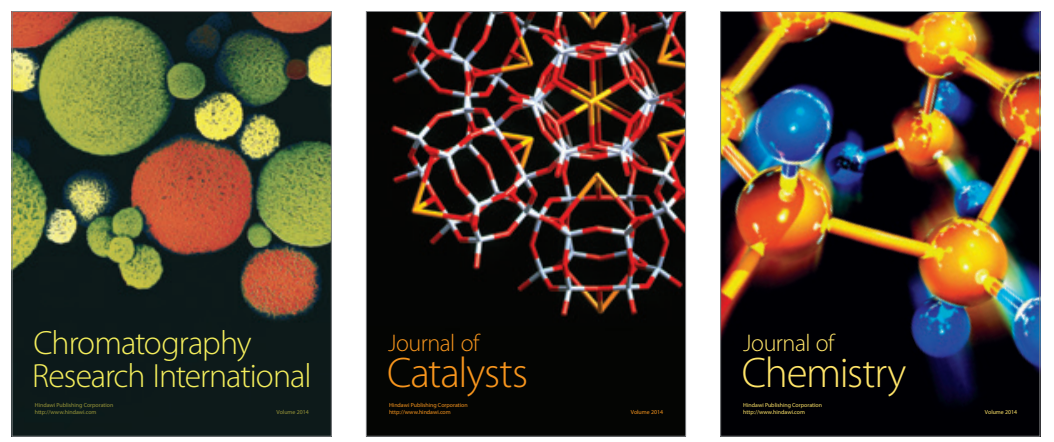
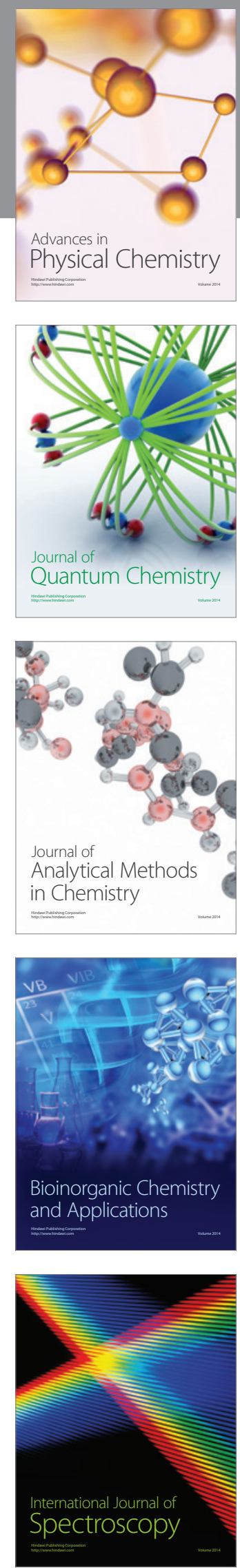